\title{
Introduction: COVID-19 and Asia
}

\author{
Anoma Phichai VAN DER VEERE, Florian SCHNEIDER, and \\ Catherine Yuk-ping LO
}

Keywords: global health governance, labour migration, Asia, public health, COVID-19, globalisation

In late 2019, the world watched closely as cases of an unknown virus causing pneumonia started spreading through Wuhan province in the People's Republic of China (PRC). Gradually, more cases were being reported, and on Saturday 11 January 2020 Chinese state media announced the first fatality (Qin and Hernández 2020). While the virus, now more commonly known as COVID-19, spread across the globe with unprecedented ease, it would take the World Health Organization (WHO) until 30 January to declare the outbreak a public health emergency of international concern (PHEIC). ${ }^{1}$ By this time, there had been 7834 confirmed cases and 170 people had lost their lives to the virus (WHO 2020a).

With the benefit of hindsight, we can now see that the virus has wreaked havoc on the world. By 30 January 2021, a year after the PHEIC announcement, almost every country and region had been hit (WHO 2021a). Over 100 million people had been infected, resulting in more than two million deaths. The interconnectedness of our modern transport systems carried people from Wuhan to ports on every continent before any viable measures were put in place, spreading the virus every where. As the outbreak developed, it was those nations that are geographically close to China, in East Asia and Southeast Asia, that especially struggled to cope with its scale. Different

1 A PHEIC is defined as 'an extraordinary event which is determined to constitute a public health risk to other states through the international spread of disease and to potentially require a coordinated international response'. This definition implies a situation that: 1) is serious, sudden, unusual or unexpected; 2) carries implications for public health beyond the affected state's national border; and 3) may require immediate international action (WHO 2008, 19).

Van der Veere, Anoma P., Florian Schneider, and Catherine Yuk-ping Lo (eds), Public Health in Asia during the COVID-19 Pandemic: Global Health Governance, Migrant Labour, and International Health Crises. Amsterdam, Amsterdam University Press 2022 DOI: 10.5117/9789463720977_INTRO 
conditions have led to different results in these countries. South Korea and Vietnam, for instance, had previously experienced the dangers of public health crises during the SARS epidemic in the early 200os, and as a result they were well-equipped to deal with the virus (see in this volume: Le \& Nicolaisen, and Nguyen for Vietnam; Howe, and Kim \& Song for South Korea). Similarly, Taiwan (ROC) was able to quickly respond to the outbreak (see Lo, and Liu), despite its connections to the PRC. However, countries like Indonesia and Japan were less prepared (see Yazid, Shibata, and Van der Veere). Meanwhile, Malaysia was suffering an acrimonious political shift that resulted in a delayed response to the developing public health threat (see Kamaruddin \& Idris).

These examples show that talking about Asia is challenging. It is the largest region on the planet, containing dozens of political systems, thousands of languages and cultures, and billions of people. Moreover, as area studies scholars have repeatedly pointed out, any attempt at defining it has political implications, making it a difficult concept to work with (see for example the contributions in Wesley-Smith and Goss 2010). Despite this theoretical ambiguity, however, the term 'Asia' has real-world uses. When we visit the websites of some of the world's largest media outlets, news from the region is frequently sorted under the banner 'Asia'. Our understanding is therefore partly formed by our consumption of the concept of 'Asia', ambiguous as it may be. ${ }^{2}$ This ambiguity offers some disadvantages, especially in a scholarly work such as this one. However, it offers one benefit. The main reason that we have chosen to use Asia in the title of the book is because of the diversity of the region. Leaning into the ambiguities that come with attempts to define the region allows us to offer contrasting and comparative perspectives that might enable a better understanding of how dynamic a region like Asia is, and why public health crises such as the COVID-19 pandemic develop in different ways even within such a region.

This book reflects this diversity by including chapters that respectively focus on different countries, regions, governments, and institutions. It offers local perspectives, local knowledge, and new information in an accessible and informative way. One of the main motivations for creating this volume has been to provide policy makers and health specialists with a better picture of the different strategies that have been employed in Asia

2 See for example BBC News, https://www.bbc.com/news/world/asia; or CNN, https://edition. cnn.com/asia. Even media outlets based in Asian countries often default to the 'Asia' category, see for example Nikkei Asia, https://asia.nikkei.com/; and the South China Morning Post, https:// www.scmp.com/news/asia. 
during the COVID-19 pandemic. It does this using thoroughly researched and informed case-studies that are presented in an accessible format. Although every country has its own context, and every institution operates in its own place and time, hopefully this volume will deepen our shared understanding of how interconnected people and institutions interact during times of crisis.

\section{The Importance of Understanding COVID-19 and Asia}

In 2019, the Nuclear Threat Initiative and the Johns Hopkins Center for Health Security published a report titled the 'Global Health Security Index' (2019). In its conclusions, the report judged countries like the United States, the United Kingdom, the Netherlands, and Brazil as being 'Most Prepared'. This was ostensibly for their ability to rapidly respond to the spread of an epidemic. The only two Asian countries deemed 'Most Prepared' were South Korea and Thailand. This was only a few months before the COVID-19 pandemic would devastate the global economy and throw international mobility into disarray. The COVID-19 pandemic, which is currently far from over, has already cost millions of lives and has shown that the list in this report was shockingly off the mark.

The supposed preparedness of different countries presented in this report is jarring considering the disorienting conditions into which the world was plunged as the pandemic spread. The constantly changing nature of the pandemic has left most observers guessing what was working well, and what was not. This has led to a wave of erroneous, often hastily constructed interpretations that have found their way into daily lived experiences. Japan is an excellent case in point. The country's government was slow to act when it was forced to deal with a cruise ship full of infected tourists in February and March 2020, early on in the pandemic. Through its ineffective handling of the situation, the government inadvertently created a cruise ship-sized COVID-19 petri-dish on the shore of Yokohama, near one of the world's most densely populated metropolitan areas. It was widely lambasted for this failure to act in the media and by other governments and institutions (Ratcliffe and Fonbuena 2020). Only two months later, however, with the number of infections stabilizing in the country but exploding abroad, the Director-General of the WHO praised Japan's approach, hailing it as a great success (Kyodo News 2020). This cycle of ascribing either failure or success, depending on the circumstances of the moment, has continued ever since. 
There has been a tendency in media reports to arrive at hasty conclusions based on circumstantial evidence. This has in turn resulted in a high level of mixed messaging. However, it would be irresponsible to lay the blame solely with the media. Government officials, policy makers, and global actors have taken part in the same game. As a consequence, such inaccuracies have also found their way into official policymaking.

One example is an international comparative country review produced by the Dutch Ministry of Labour, Welfare and Sports. This report was written to inform the Dutch government about varying approaches to maintaining public health during the COVID-19 pandemic. The two health policy specialists who authored the report found it helpful for their understanding of Asia to include South Korea as a case-study. They employed the Hofstede model of national culture to frame their understanding of South Korea and indirectly the 'Asian approach'. Despite the wide-spread criticisms of the Hofstede model, it continues to be used as if it reliably represents factual and objective scientific analysis. It is beyond the scope of this volume to delve into the many problems with the model, ${ }^{3}$ but it is helpful to quote a particular section from the aforementioned report in order to illustrate how this model is used to make problematic arguments about the success of the South Korean public health model:

\begin{abstract}
A large difference becomes clear from the observation that South Korean society is a lot more collectivist. [...]. ${ }^{4}$ Moreover, as South Korean society is primarily feminine this leads to most people realizing that everyone is part of a group or that their role is to protect vulnerable people. [...]. To conclude, South Koreans are less abundant than Dutch people. This makes it easier for them to follow measures that restrict freedom for longer periods of time (Hagenaars and Jeurissen 2020, 12). ${ }^{5}$
\end{abstract}

3 The Hofstede model is by and large a collection of statistical information based on fallacious assumptions, yet it has remained popular as a measure for 'national cultures'. We agree here with Brendan McSweeney's description of the model as methodologically flawed and 'a restrictor not an enhancer of understanding particularities' (2002, 112). McSweeney also states that 'the identification claims are fundamentally flawed and the attribution of national level actions/ institutions to national cultures is an easy but impoverishing move'.

4 The part left out of the quotation above reads: 'And where the Netherlands is slightly risk averse and pragmatic, South Korea is very risk averse and extremely pragmatic. Both of these issues contribute to a culture that is able to change gears quickly and powerfully when necessary in the face of an emerging infectious disease.'

5 Author translation. For readers wondering if a translation of the complete section will add relevant context that will lead to the salvation of the report's conclusions, I can assure you none exists. 
All of the above statements can be disproven point by point. More importantly, the authors have chosen to eschew a thorough analysis that critically analyses domestic measures in the context of a more successful approach. Instead, they present their findings in a way that serves to justify their own set of (ineffective) public health measures - and even the hesitancy to implement such measures - in the context of the Netherlands. The conclusion ignores any political factors that may have caused Dutch people to be more hesitant towards public health measures. It also does not address the possible causes of civil compliance among South Koreans, such as previous experience with public health crises, national interests, or the evolution of transnational political discourses on public health. Instead, the population is deemed collectivist, feminine, and less abundant.

Interestingly, an early survey study showed that in countries including the Netherlands 'public belief in the effectiveness and the actual implementation of certain protective measures during the early phase of the COVID-19 pandemic in March 2020 was high' (Meier, et al. 2020). The decline in social compliance of Dutch people in the later months of the pandemic can therefore be better attributed to a set of obviated domestic circumstances that the authors of this report fail to address. Given this missed opportunity, or possibly in spite of it, the authors attempt to explain away public resistance in the Netherlands through naturalistic comparisons with the South Korean population. Their report is an excellent example of how actors outside of Asia frequently misunderstand, or even wilfully misrepresent, the politics and cultures of the region. Such actors use the regrettably widespread public ignorance regarding Asia to dismiss governance approaches that clash with entrenched habits and ideologies.

Of course, not all policy-makers dismiss Asia as callously as the authors of this Dutch policy report; many are aware that there are lessons to be learned. There is then a serious need for informed case studies that highlight the most important issues in an accessible, concise manner. This book seeks to do this. For example, it covers the South Korean case in two chapters. The first of these details and contextualizes the South Korean government's national interests within a framework of global health governance (Howe). The second chapter then explains how official and public sentiments have affected South Korea's relations with the WHO (Kim \& Song). These and other case studies in this volume offer a wealth of in-depth information about how different governments, organizations, and political actors across the Asian region have handled COVID-19. 


\section{Global Health Governance and Asia}

Under the strain of our world's ever increasing interconnectedness, the global system of health governance currently in place has come under increasing pressure. As the largest health institution in the world, the WHO's role in responding to the COVID-19 pandemic has been widely criticized for being slow and inefficient, and even for ostensibly appeasing China, where the virus originated. While governments were scrambling to respond to the emerging threat of COVID-19, the pandemic became increasingly politicized. Over the course of the pandemic, the line between public health concerns and political contestation has been blurred and the effects of already existing international political tensions have been magnified. An example of this was China's so-called 'mask diplomacy', where it sought to win the favour of other countries through the supply of masks and medical equipment (see Satoh). Another example is the high-profile political debates about the exact origins of the virus that have occurred in several different countries, particularly in the US.

The health-politics nexus is further demonstrated in the case of the WHO's declaration of a PHEIC. The WHO has had the responsibility for determining when an outbreak is a global public-health emergency since 2005. However, it has only done this five times prior to the COVID-19 pandemic: during the swine-flu pandemic in 2009; the Ebola outbreaks in West Africa in 2014 and in Congo in 2019; the emergence of polio in war zones in 2014; and the Zika epidemic in 2016. The amount of time it has taken for the WHO to declare a particular situation a PHEIC has nevertheless been a focal point of criticism. For instance, during the $2009 \mathrm{H}_{1} \mathrm{~N}_{1}$ outbreak, it took the $\mathrm{WHO}_{3} 8$ days to declare a PHEIC after laboratories isolated HiN1 on 18 March 2009. In sharp contrast to the speed of global action regarding $\mathrm{H}_{1} \mathrm{~N} 1$, a PHEIC was not declared until 138 days after the first detected case of Ebola in West Africa on 22 March 2014 (Hoffman and Silverberg 2018, 330). ${ }^{6}$

The reason why the WHO declares, or does not declare, a particular situation as a PHEIC has been another point of criticism. Critics have argued that the WHO's decision is based on the economic conditions of the affected countries. The Ebola outbreak in 2014 is a case in point. A leaked document shows that the WHO intentionally delayed declaring a PHEIC for the sake of avoiding catastrophic economic consequences for Guinea and other afflicted

6 The H1N1 outbreak began on 15 March 2009, was detected on 18 March 2009, and was declared a PHEIC on 25 April 2009. The West African Ebola outbreak began on 26 December 2013, was detected on 22 March 2014, and was declared a PHEIC on 8 August 2014. 
countries (Boseley 2015). A study conducted by Hoffman and Silverberg (2018, 331) indicates that the direct impact of infectious diseases on the US is also a necessary condition for a global health emergency pronouncement. A PHEIC was declared ten days after the first US citizen was detected with the $\mathrm{H}_{1} \mathrm{~N} 1$ infection. Meanwhile, Ebola was declared a PHEIC just six days after infected health care providers arrived in the US for treatment on 2 August 2014.

When COVID-19 hit at the start of 2020, the WHO was blamed for serving the interests of the Chinese government. Social media users have mocked the WHO as 'Winnie the Pooh Health Organization', referencing the common practice among Chinese Internet users of comparing Chinese President Xi to Winnie the Pooh (McDonnell 2017). Others have referred to the $\mathrm{WHO}$ as $\mathrm{CHO}$ (Chinese Health Organization) to express their anger about the way that the WHO is supposedly managing the pandemic in line with Chinese interests (see Van der Veere). The US and countries in Europe have condemned the WHO for being vulnerable to Chinese influence. This susceptibility is exemplified in the eyes of critics by the fact that Taiwan, also called the Republic of China (ROC), has not been invited to attend the World Health Assembly (WHA), the highest decision-making body within the WHO, since 2017 (see Lo).

In the process, the legitimacy of the WHO has gradually been eroded. Although we can attribute a certain degree of this erosion to global perceptions of its response, we also need to understand the current state of the organization and the way it functions. Established in 1948 as a specialized agency of the United Nations (UN), the WHO is currently the most comprehensive global health organization, tasked with preventing the global spread of diseases and promoting better health around the world. The WHO has a decentralized structure, operating from its Geneva headquarters and six regional offices. The Secretariat, headed by the Director-General, is responsible for the dayto-day operations of the health agency in collaboration with the regional and country offices. The Director-General is appointed by and responsible to the World Health Assembly (WHA) that sets the agenda and approves the budget of the WHO during the annual meeting held in Geneva, Switzerland.

The WHO's budget operates on a two-year cycle, and in 2018-2019, it received US $\$ 4.4$ billion. To place this number in perspective, this is less than that of a typical major hospital system in the US (McKeever 2020). The organization receives its funding from two main sources. The first of these is assessed contributions, payable by its 194 Member States. ${ }^{7}$ The

7 The amount of the assessed contributions each Member State must pay is calculated relative to the country's wealth and population (See WHO 2021). 
second source is voluntary contributions made by Member States (in addition to their assessed contributions), by other UN organizations, as well as by intergovernmental organizations, philanthropic foundations, and the private sector.

The size of assessed contributions, which are a key source of WHO financing, declined following the 2008/og global financial crisis. To date, about $80 \%$ of the WHO's funding comes from voluntary contributions (WHO 2021a). It is important to note that $96.1 \%$ of all voluntary donations should be spent either according to the contributors' priorities, or are tied to specific programme areas and/or geographical locations and must be spent within a specified timeframe (WHO 2021a). ${ }^{8}$ In other words, the WHO only has full discretion over approximately $3.9 \%$ of all voluntary contributions. This therefore means that the WHO has limited financial autonomy to initiate new programmes for advancing overall global health.

The WHO seemed set to encounter a budget crisis at the start of the COVID-19 pandemic. As the biggest single donor, accounting for $15 \%$ of the WHO's biennial budget in 2018-2019 (McKeever 2020), the US suspended its funding in April 2020. Under the administration of former US president Donald Trump, the US withdrew from the WHO in July 2020, accusing the organization of being too slow to respond to the outbreak in China and being too deferential to the Chinese government (Alpert 2020). The Biden administration has since halted the US withdrawal from the WHO. However, it is widely believed that funding for the WHO still needs to be diversified to pre-empt future budget crises triggered by the withdrawal of key contributors. The availability of sufficient funding is crucial for the WHO to facilitate timely responses in emergency situations, including global infectious disease outbreaks.

In addition to budgetary constraints, the WHO functions under a specific set of rules: the International Health Regulations (IHR). This is a legalbinding global agreement for addressing the risks of the international spread of infectious diseases and is also geared to avoiding unnecessary interference with international travel and trade (WHO 2008). The first version of the legal framework, the International Sanitary Regulations (ISR), was issued in 1951, and there have been a number of revisions since then. Following the eradication of smallpox in 1980, the WHO revised the IHR in 1981 to focus

8 The voluntary contributions are further categorized based on the degree of flexibility the WHO has in deciding how to spend these funds. These are fully flexible core voluntary contributions $(3.9 \%)$, partially flexible thematic and strategic engagement funds $(6 \%)$, and non-flexible specified voluntary contributions (90.1\%; WHO 2021). 
solely on three diseases: cholera, yellow fever, and plague. After the outbreak of Severe Acute Respiratory Syndrome (SARS) in 2003, the organization again revised the IHR in 2005, with these revisions entering into effect in 2007.

This current version of the IHR, also referred to as IHR (2005), has a much broader scope of application than earlier versions, covering 'all events potentially constituting a public health emergency of international concern (PHEIC)' (WHO 2008, 19). The current IHR took into account the reluctance of the Chinese government to share information during the early stages of the outbreak of SARS in 2013. As a result, the current IHR was revised to guarantee that event-related information provided by the country that is notifying the organization about a disease outbreak is not shared with other countries before the WHO has announced that there is a PHEIC. This mechanism aims to 'protect affected countries from any unjustified overreaction by other countries' (WHO 2008, 19). Following an official PHEIC announcement, the WHO is allowed to share information concerning an outbreak with member states.

In addition to enabling information sharing, the declaration of an outbreak as a PHEIC also allows the WHO to activate its funding channels to grapple with global health emergencies in a short period of time. The first WHO funding channel is the Contingency Fund for Emergencies (CFE). Established in 2015, the CFE aims to remedy the WHO's chronic budget deficit and the overdependence on voluntary contributions, allowing the organization the flexibility to scale up operations during disease outbreaks and health emergencies. Funding from this mechanism can be released in less than 24 hours and utilized for financing immediate response activities. One month after declaring COVID-19 a PHEIC, the CFE had provided US $\$ 8.9$ million for COVID-19 when no other funding was available (WHO 2021b). The WHO then called for US $\$ 675$ million in the Strategic Preparedness and Response Plan (SPRP), another WHO funding channel, after the PHEIC declaration was made (WHO 2020a). The WHO has reached the target, having received US $\$ 677$ million from its member states by 1 April 2020 (WHO 2020a). The COVID-19 Solidarity Response Fund is the third funding channel through which individuals, philanthropists, and businesses are able to contribute to WHO-led efforts in responding to public health crises. This Solidarity Response Fund received more than US $\$ 108$ million in donations from over 203,000 individuals and organizations in the first two weeks after the WHO officially declared COVID-19 to be a PHEIC (WHO 202ob).

While this PHEIC-induced global financial mobilization has been quite successful in the case of COVID-19, overall compliance of member states with the IHR has been questionable. For example, the IHR (2005) requires 
member states to strengthen or re-establish the public health infrastructures designed to facilitate early recognition of, and rapid response to, emerging diseases. As part of their commitment to the IHR, participating countries agreed to comply with these rules by 2012 . However, only about one-third of participating countries (64 countries) reported fully achieving the core capacities by 2014 (Gostin and Katz 2016, 276). ${ }^{9}$ Based on these figures, it is not surprising to see that many countries were not ready to deal with COVID-19. It remains to be seen whether countries' approaches to compliance with the IHR have changed as a result of the pandemic.

Apart from the limitations of voluntary compliance with the IHR, we have seen an erosion of member states' trust in the WHO. As globalization has pushed the integration of national economies to the point of interdependence, transportation systems have developed along the same lines. This means that a country cannot physically isolate itself from the rest of the world without inflicting economic damage on itself. As the pandemic hit, an urgent concern for national governments was therefore controlling the in- and outflow of people, especially tourists and migrants. When COVID-19 was declared a PHEIC, the WHO simultaneously advised states to keep borders open on the basis of the IHR. However, almost every country ignored the WHO's advice, and many countries even closed their borders to all nations (Mallapaty 2020), leading to an unprecedented crisis for migrant workers in a number of Asian countries (See Part IV of this book).

In this sense, the complete lockdown of Wuhan in China set an example (see Lo). However, other countries and regions also took measures that affected how human beings could move across space. Foreign workers were barred from entering or leaving Japan, often stranding them abroad away from their jobs, homes, and families. Meanwhile Taiwan's exclusionary guest worker policy made it practically impossible to include all migrants in public health strategies dealing with the pandemic (see Liu). In the case of Indonesia, a country that sends more workers abroad than it receives, a wave of returning migrant workers exerted sudden pressure on the country's healthcare system (see Yazid). The mobility of foreign workers is intricately

9 According to the IHR (2005), member states of the WHO are required to submit a selfevaluation of their core capacities for emergency preparedness and responses. The designated thirteen core capacities include: (1) Legislation and financing; (2) IHR Coordination and National Focal Point Functions; (3) Zoonotic events and the Human-Animal Health Interface; (4) Food safety; (5) Laboratory; (6) Surveillance; (7) Human resources; (8) National Health Emergency Framework; (9) Health Service Provision; (10) Risk communication; (11) Points of entry; (12) Chemical events; and (13) Radiation emergencies. 
linked with global health governance and any strategy to contain a pandemic has to account for the inherently transnational nature of public health crises.

As the case-studies in this volume also show, these developments can have devastating long-term effects for the future of global health governance. This is especially as public trust in governments during health crises has previously proven to be reliant on cooperation with the WHO (see Ishikawa \& Kohara). To regain public trust, some WHO member states called for a more in-depth investigation into the origin of the virus during the WHO's annual decision-making meeting, the World Health Assembly (WHA) in May 2021. This was after an international mission to China earlier the same year proved inconclusive (Larson 2021).

The WHO's investigation and report have also faced criticism for failing to include all essential data, as well as for not fully evaluating theories that COVID-19 was the result of a leak from a laboratory located in the Wuhan area (Miller, Nebehay, and Farge 2021). Critics allege that the WHO has been too deferential to China in its handling of the COVID-19 pandemic and its sharing of data concerning viral origins. They argue that a drastic reform of the WHO is needed to avoid future COVID-like crises. Among the recommendations for the organization's reform are measures to boost the WHO's independence, to give it the power to investigate serious health threats in countries concerned, and to allow it to sound the alarm about risks without waiting for the green light from the countries that have notified it about disease outbreaks (Larson 2021). In the absence of a meaningful reform, it cannot be assumed that the WHO will have an appropriate response to future global health crises. Neither can it be assumed that national governments will listen to the WHO's advice.

\section{Overview of the Volume}

This volume is organized around four themes: health policy in Asia and the global community; the future of global health governance in Asia; domestic responses to COVID-19 in a globalized Asia; and migrant workers and the global economy during COVID-19.

Part I of the book is devoted to an assessment of health policy in Asia and the interactions between the agencies at national, regional, and global levels in times of infectious disease outbreaks. Satoh, for example, highlights the inherent deficiency of the UN system, showing that differences between political values among member states and the principle of upholding state sovereignty make joint actions difficult. This has been demonstrated during the COVID-19 pandemic. The WHO has been unable to make China 
accountable for their poor track record of transparency, issuing guidelines that member states can easily ignore. Moreover, the WHO has been vulnerable to great power competition between the US and China, undermining coordinated disease responses at both regional and global levels. Satoh argues that US action (or inaction) has been by far the most consequential in undermining the confidence of the global community towards the WHO.

In contrast, Koga argues that the Association of Southeast Asian Nations (ASEAN), the key regional organization in Asia, has made a successful effort to build its own capacity to tackle emerging infectious diseases (EIDs). Koga demonstrates how ASEAN's mechanisms to tackle EIDs were been developed prior to the COVID-19 outbreak. ASEAN's health governance efforts were initiated during the Cold War against the backdrop of great power rivalry, long before the COVID-19 outbreak took place. An acceleration of the institutionalization of health cooperation among ASEAN member states then occurred after the SARS outbreak in 2003.

Criticism of the functioning of the WHO has been prolific. However, while critiques of the WHO and the UN system are valid, Ishikawa \& Kohara show that the WHO has nevertheless played a positive role in countries encountering infectious disease outbreaks. In their chapter they offer a statistical investigation into public levels of trust in selected Asian countries before and after the 2003 SARS outbreak. They demonstrate that public trust in government dropped in the countries that were seriously affected by SARS. However, they further show that the deterioration in trust was alleviated in countries hosting a WHO collaborating centre in a domestic research institute. This suggests that such collaboration with the WHO can mitigate declining public trust in national governments during public health crises.

Part II of the book, taking into account the function of the WHO in coordinating disease responses in Asia, attempts to envision the role of the institution in global health governance in the future. Gong \& $\mathrm{Li}$, for example, assess Chinese influence on the WHO and the role of China in global health governance. They argue that Chinese leadership potential has been constrained by several factors. Among these factors, two of the most important are the relatively low contributions that China makes to the funding of the $\mathrm{WHO}$ when compared to traditional donors as well as China's illiberal and fragmented domestic governance structure. As such, it is misleading to assume that China will have sufficient resources to lead global health governance, despite the declining role of the US.

Looking at the attitudes towards the WHO of Asia's other leading power, Van der Veere shows that Japan viewed the WHO as a neutral and scientific source of information during the outbreaks of SARS, Middle East Respiratory 
Syndrome (MERS), and COVID-19. It has often used specific information from the WHO to justify domestic policy goals. However, trust in the organization among policymakers has faltered due to its connection with China. Van der Veere argues that the importance of the WHO in Japan has declined and will continue to do so as long as the organization's neutrality is in doubt, and as long as its guidelines and advice conflict with the country's domestic agenda.

In contrast with the Japanese case, Howe shows that the Republic of Korea (ROK) has seized the opportunity provided by COVID-19 to present itself as a health leader on the world stage. It has positioned itself as an exemplary member state to the WHO over the course of the COVID-19 pandemic. The ROK has not only followed and promoted WHO guidelines, but has also been at the forefront of developing measures to combat COVID-19. Howe further argues that South Korea, as a middle power, is likely to continue its support of the WHO and increase its contribution as a global player in the field of health governance.

While South Korea has increasingly contributed to global health governance, it has frequently been argued that the role of Taiwan in global health governance has remained minimal because of its ambiguous international status and the increasing pressure exerted on it by the People's Republic of China (PRC). Offering a contrasting argument, Lo instead posits that the de facto status of Taiwan may allow it to escape the so-called 'realist trap' that state actors often encounter in global health governance. This trap describes the way that states seeking to engage in international cooperation face problems such as freeriding or failure to comply with existing norms and regulations. In escaping this trap, Lo argues that Taiwan has the potential to participate in global health governance in a meaningful way.

Part III of the book consists of a number of contributions examining domestic responses to COVID-19 in Asia. These case studies explore the various factors that have contributed to, or impeded, an effective response to COVID-19, and their effects on the local population. For example, Nguyen shows that Vietnamese measures to respond to COVID-19 were taken ahead of recommendations made by the WHO in the early stages of the global outbreak. The chapter also shows how the early responses and strict policies adopted in Vietnam have limited the spread of COVID-19 in the country. Yet, despite Vietnam's relative success during 2020, Nguyen also demonstrates the socio-economic impacts that COVID-19 has had on healthcare in Vietnam, calling for the provision of social support to those who are most vulnerable during public health crises.

The chapter by Le \& Nicolaisen describes further underlying factors that have led to the success of the Vietnamese response to COVID-19, namely the 
timeliness in implementation of policies, the country's prior experiences in infectious disease crises, the transparency in communication, and the active social mobilization. Drawing on the extensive research of Vietnam they have conducted in the past, Le \& Nicolaisen argue that the political legitimacy gained by the Vietnamese government could diminish once the pandemic is over. They suggest that this could occur if there is a reversal of transparent communication or a continuation of economic uncertainties during the post-COVID-19 era.

While fast action helped contain the spread of COVID-19 in Vietnam, in their chapter Kamaruddin \& Idris demonstrate that there are more factors than rapid responses in play. They show that the Malaysian government was in the middle of political unrest when COVID-19 struck and had to scramble to respond appropriately. Accordingly, Kamaruddin \& Idris highlight how a professional and well-established civil service system can also be key to shaping a country's pandemic response, even in times of political crises.

However, countries' actions in response to COVID-19 have not only been domestically focused. Kim \& Song show how, in its response to COVID-19, the South Korean government quickly embraced multilateralism. It provided financial resources to key global health initiatives for fair and equal access to COVID-19 vaccines, established global platforms for dialogue, and enhanced its participation in global health institutions. They further demonstrate how the South Korean government has displayed consistent support for the WHO despite swaying public sentiments in South Korea toward the WHO's management of the situation, and a wavering public position towards China.

Part IV, the final section of the book, takes a closer look at the effects of COVID-19 on workers in different Asian nations, in particular non-regular workers and migrant workers. It examines the socio-economic impacts of COVID-19 related measures in societies in Asia. To start this section, Lo discusses the economic and political repercussions on the Chinese economy of the COVID-related Non-Pharmaceutical Interventions (NPIs). Considering the ongoing Sino-US trade disputes and the rising suspicion of China and Chinese firms in the US and Europe, this chapter asks to what extent the Chinese Communist Party (CCP) will be able to save its performative legitimacy through the new economic strategy dubbed the 'dual circulation strategy'. It looks at the implications of Chinese economic reforms in the post-COVID-19 era.

With economic reforms likely to follow after the COVID-19 pandemic in different countries, changes to the mobility and health conditions of migrant workers need to be understood. A chapter by Liu presents Taiwan's successful experience in dealing with the COVID-19 pandemic during 2020. It also shows, 
however, how the pandemic has exposed the vulnerability of migrant workers in Taiwan, who often lack healthcare access and financial support. Presenting these problems faced by migrant workers in Taiwan, Liu calls for changes to the 'divide and exclude' guest worker policy that leaves migrant workers facing dire working conditions and unable to access basic health services.

Low-wage and migrant workers seem to be among the most vulnerable groups during public health crises, when existing inequalities are magnified. In a chapter looking at Japan, for example, Shibata shows how the problems faced by Japanese workers during the COVID-19 pandemic can be best understood when seen through the lens of the country's on-going neoliberal reforms and when changes in Japan's labour market and public health system are taken into consideration. Shibata argues that the problems that Japanese workers face in the labour market and the welfare system have created a number of obstacles to the successful management of the pandemic and the necessary public health interventions. The chapter concludes that the WHO needs to consider the impacts of nation-specific, socio-economic institutions on public health to improve the formulation of its recommendations regarding how to respond to global health crises such as COVID-19.

While Japan is a country that receives migrant workers, Indonesian workers mostly migrate to other countries. The chapter by Yazid describes how Indonesia has responded to the COVID-19 outbreak, which has seen a wave of returnees arriving in the country. Yazid shows that Indonesia's responses are essentially in line with the recommendations of the International Labour Organization (ILO). However, like the arguments made by Shibata about the WHO, Yazid argues that global institutions, in particular the ILO, should take into account the specific characteristics and needs of each country when formulating a global response.

The COVID-19 pandemic has made it clear that public health crises are complex and dynamic processes. As the case-studies in this volume show, we need to thoroughly understand how certain actions result in particular consequences. Even if a response is quick and effective, as in the cases of Vietnam and Taiwan (ROC), there are still segments of the population that can suffer under the new measures put in place. Socio-economically vulnerable groups, such as low-income informal workers, or immigrant workers, are especially prone to marginalization. The success of a response to a sudden public health crisis is therefore not only determined by the number of infections, but by the long-term effects on the public.

Moreover, the politicization of public health has impeded the implementation of a unified global response. This extends from the great power politics between China and the US to the prioritization of a domestic agenda in the 
case of Japan. Across Asia we see that public opinion has a lasting effect on how effective governments can be in responding to new crises. Public trust is quickly eroded and there are only a few means by which governments can try to re-establish a higher level of legitimacy. Domestically, they might do this through transparent communication, rapid and strict responses, media effects, or scientific cooperation with the WHO.

At the same time, however, we have to realize that public health and public trust are transnational. They cross borders, and this is where the politics between nation-states once again come to the fore. Over the course of the COVID-19 pandemic, this has forced multilateral and global institutions like ASEAN, the WHO, and the ILO to play a game of catch up, some more successfully than others. It is therefore paramount for policy makers, health specialists, and the public to realize that health governance is not simply a matter of scientific facts, but a goal that keeps changing, requiring policy makers and citizens alike to adjust to dynamic circumstances.

If this volume can offer one takeaway, it would be this: Asia is diverse, and this diversity has practical, real-world consequences. Understanding the way that Asian countries and regions have variously responded to the COVID-19 pandemic goes beyond the binaries of 'success' and 'failure', 'national' and 'global'. The diverse responses showcase a mixture of causes and consequences that continuously come together or fall apart. We do not know when the next global health crisis will strike, but we know that the complexities of our interconnected world make such a crisis almost inevitable. This makes it essential to look at Asia, to learn lessons where they are available, and to ensure our societies are better prepared and more resilient the next time around.

\section{References}

Alpert, Lukas I. 2020. 'World Health Organization Projects \$1.3 Billion Shortfall in Fighting Covid-19.' The Wall Street Journal, 20 May. Accessed 17 June 2021. https://www.wsj.com/articles/world-health-organization-projects-1-3-billionshortfall-in-fighting-covid-19-11590008871.

Boseley, Sarah. 2015. "“World Health Organization” Intentionally Delayed Declaring Ebola Emergency.' The Guardian, 20 March. Accessed 17 June 2021. https://www. theguardian.com/world/2015/mar/2o/ebola-emergency-guinea-epidemic-who.

Gostin, Lawrence O. and Rebecca Katz. 2016. 'The International Health Regulations: The Governing Framework for Global Health Security.' The Milbank Quarterly vol. 94: 264-313. 
Hagenaars, Luc, and Patrick Jeurissen. 2020. Strengheid van het Lockdown Beleid in de Bestrijding van COVID-19, en de Mate waarin deze aansluit bij Nationale Culturen:Een Internationale Vergelijking. Official Exploratory Study, The Hague: Ministerie van Volksgezondheid, Welzijn en Sport.

Hoffman, Steven J. and Sarah L. Silverberg. 2018. 'Delays in Global Disease Outbreak Responses: Lessons from $\mathrm{H}_{1} \mathrm{~N}_{1}$, Ebola, and Zika.' American Journal of Public Health vol. 108: 329-333.

Kyodo News. 2020. 'WHO Head Deems Japan's Battle against Coronavirus a “Success".' Kyodo News, 26 May. Accessed 1 June 2021. https://english.kyodonews.net/ news/2020/05/5bbe50741ceb-who-head-deems-japans-battle-against-coronavirus-a-success.html.

Larson, Nina. 2021. 'Countries Urge Deeper Probe of Covid Origins at WHO Meeting after China Mission Inconclusive. Hong Kong Free Press, 26 May. Accessed 18 June 2021. https://hongkongfp.com/2021/05/26/countries-urge-deeper-probeof-covid-origins-at-who-meeting-after-china-mission-inconclusive/.

Mallapaty, Smriti. 2020. 'What the Data Say About Border Closures and COVID Spread.' Nature, 22 December. Accessed 18 June 2021. https://www.nature.com/ articles/d41586-020-03605-6.

McDonell, Stephen. 2017. 'Why China Censors Banned Winnie the Pooh.' BBC News, 17 July. Accessed 25 June 2021. https://www.bbc.com/news/ blogs-china-blog-40627855.

McKeever, Amy. 2020. 'Here's What We Will Lose if the U.S. Cuts Ties with the WHO.' National Geographic, $11 \mathrm{July.} \mathrm{Accessed}$ 17 June 2021. https://www.nationalgeographic.com/science/article/ what-we-will-lose-if-united-states-cuts-ties-with-world-health-organization.

McSweeney, Brendan. 2002. 'Hofstede's Model of National Cultural Differences and their Consequences: A Triumph of Fate - A Failure of Analysis.' Human Relations vol. 55, no. 1: 89-118. https://doi.org/10.1177/0018726702551004.

Meier, Karien, Toivo Glatz, Mathijs C. Guijt, Marco Piccininni, Merel van der Meulen, Khaled Atmar, Anne-Tess C. Jolink, Tobias Kurth, Jessica L. Rohmann, and Amir H. Zamanipoor Najafabadi. 2020. 'Public Perspectives on Protective Measures during the COVID-19 Pandemic in The Netherlands, Germany and Italy: A Survey Study.' PLoS ONE vol. 15, no. 8. https://doi.org/10.1371/journal. pone.0236917.

Miller, John, Stephanie Nebehay, and Emma Farge. 2021. 'WHO Official Says Can't Force China to Give More Information on COVID-19 Origins.' Reuters, 8 June. Accessed 18 June 2021. https://www.reuters.com/world/china/who-officialsays-cant-force-china-give-more-information-covid-19-origins-2021-06-07/.

NTI and the Center for Health Security, Johns Hopkins Bloomberg School of Public Health. 2019. 'GHS Index: Global Health Security Index.' Accessed 
20 January 2021. https://www.ghsindex.org/wp-content/uploads/2020/04/2019Global-Health-Security-Index.pdf.

Qin, Amy, and Javier C. Hernández. 2020. 'China Reports First Death from New Virus.' The New York Times, 11 January. Accessed 1 June 2021. https://www.nytimes. com/2020/01/10/world/asia/china-virus-wuhan-death.html.

Ratcliffe, Rebecca, and Carmela Fonbuena. 2020. 'Inside the Cruise Ship that Became a Coronavirus Breeding Ground.' The Guardian, 6 March. Accessed 1 June 2021. https://www.theguardian.com/global-development/2020/mar/o6/inside-thecruise-ship-that-became-a-coronavirus-breeding-ground-diamond-princess.

Wesley-Smith, Terence \& Goss, Jon (eds). 2010. Remaking Area Studies: Teaching and Learning Across Asia and the Pacific. Honolulu, HI: University of Hawaii Press. WHO. 2008. 'WHO Guidance for the Use of Annex 2 of the International Health Regulations (2005).' Accessed 17 June 2021. https://www.who.int/ihr/revised_annex2_guidance.pdf.

- 2020a. 'WHO Director-General's Opening Remarks at the Mission Briefing on COVID-19.' 2 April. Accessed 17 June 2021. https://www.who.int/directorgeneral/speeches/detail/who-director-general-s-opening-remarks-at-themission-briefing-on-covid-19---2-april-2020.

- 202ob. 'WHO Director-General's Opening Remarks at the Media Briefing on COVID-19.' 27 March. Accessed 17 June 2021. https://www.who.int/dg/speeches/ detail/who-director-general-s-opening-remarks-at-the-media-briefing-oncovid-19---27-march-2020.

-. 2021a. 'How WHO is Funded.' Accessed 17 June 2021. https://www.who.int/ about/funding.

-. 2021b. 'Weekly Operational Update on COVID-19.' 1 March. Accessed 17 June 2021. https://www.who.int/docs/default-source/coronaviruse/wou_2021_1march2021. pdf?sfvrsn=18bidb33_1.

\section{About the Authors}

Anoma Phichai VAN DER VEERE is a Researcher of Modern Asia within the Leiden Asia Centre at Leiden University, and a Research Fellow at the IAFOR Research Center at the Osaka School of International Public Policy. He is currently based at Osaka University, Japan, and has published on health and labour policy, sports, technology, and human rights in Asia and Europe. His latest publications include: 'Japan's Fragmented Response: Technology, Governance, and COVID-19' (Leiden Asia Centre, 2020), 'The Tokyo Paralympic Superhero: Manga and Narratives of Disability in Japan' (Asia Pacific Journal: Japan Focus, 2020), and 'The Technological Utopia: 
Mimamori Care and Family Separation in Japan' (AsiaScape: Digital Asia, 2019). He is currently the principal investigator in the Road to Tokyo 2020 project about local policymaking in disability sports in Tokyo in the run-up to the 2020 Olympic and Paralympic Games, and the 'Understanding the Limitations and Future of Transnational Migrant Labor and Global Health Governance in Asia' project, both funded by the Leiden Asia Centre.

Catherine Yuk-ping LO is an Assistant Professor at University College Maastricht, Maastricht University. She specializes in international relations and global health. Her current research interests include HIV/AIDS in China and India, infectious disease responses in Northeast and Southeast Asian states, antimicrobial resistance (AMR) challenges in the Global South and North, and also global health diplomacy. She is the author of HIV/AIDS in China and India: Governing Health Security (Palgrave Macmillan, 2015). Her book won the 2017 International Studies Association (ISA) Global Health Section Book Prize. Her works appear in such journals as the Australian Journal of International Affairs, Health and Policy Planning, Globalization and Health, and the Journal of Global Security Studies.

Florian SCHNEIDER, PhD, Sheffield University, is Senior University Lecturer in the Politics of Modern China at the Leiden University Institute for Area Studies. He is managing editor of Asiascape: Digital Asia, director of the Leiden Asia Centre, and the author of three books: Staging China: The Politics of Mass Spectacle (Leiden University Press, 2019, recipient of the ICAS Book Prize 2021 Accolades), China's Digital Nationalism (Oxford University Press, 2018), and Visual Political Communication in Popular Chinese Television Series (Brill, 2013, recipient of the 2014 EastAsiaNet book prize). In 2017, he was awarded the Leiden University teaching prize for his innovative work as an educator. His research interests include questions of governance, political communication, and digital media in China, as well as international relations in the East-Asian region. 
A Amsterdam

U University

P Press 